\title{
SOBRE A FUNÇÃO SEMÂNTICA DOS PREDICADOS
}

\author{
Celso Braida \\ Universidade Federal de Santa Catarina
}

\begin{abstract}
Resumo: Nesse texto são apresentadas as propostas de Davidson (2005) e de Puntel (2008) sobre 0 conteúdo semântico sentencial e o conceito de predicado. Na ortodoxia semântica, a função semântica dos predicados é distinta da função semântica dos designadores, o que implica que uma sentença expresse um conteúdo semântico estruturado. As propostas de Davidson e de Puntel são ambas reelaborações da proposta de Tarski (1983), pela qual as expressões predicativas são derivadas do conceito mais primitivo de sentença aberta, e do primado da verdade sentencial sobre os demais conceitos semânticos. A consequência de ambas as teorias é a eliminação do conceito de predicado e também a dispensa da tese da estruturalidade do conteúdo semântico. Sugere-se a recusa dessas propostas sob o argumento de que elas são incompatíveis com as melhores teorias tanto linguísticas e quanto formais. 0 ponto crítico está na eliminação da diferença lógica e gramatical entre indicar um objeto sem determinálo (nomear) e indicar um objeto por meio de uma determinação ou classificação (predicar), diferença essa refletida na distinção entre termo singular e termo geral na semântica tarskiana, os quais ambos são necessários para compor um termo sentencial que pode ser verdadeiro ou falso.
\end{abstract}

Palavras-chave: Semântica; proposição; predicação; estruturalidade.

\begin{abstract}
In this text are presented the proposals of Davidson (2005) and Puntel (2008) about semantic content of sentences and predication. The semantic function of predicates is traditionally distinct from the function of designators, which implies that a sentence expresses a structured semantic content. The theories of Davidson and Puntel are both reworkings of one proposed by Tarski (1983), in which the predicative expressions are derived from the most primitive concept of open sentence, and the sentential truth is the most basic semantic concept. The consequence of both theories is the elimination of the predicate concept and also the dismissal of the thesis of structurality of semantic content. It is suggested that these proposals be rejected on the grounds that they are incompatible with the best linguistic and formal theories. The critical point is the elimination of the logical and grammatical difference between indicating an object without determining it (naming) and indicating an object by means of a determination or classification of it (predication), a difference that is reflected in the distinction between singular and general terms in taskian semantics, both which are necessary to compose a sentential term that can be true or false.
\end{abstract}

Keywords: Semantics; proposition; predication; structurality.

O problema da descrição do conteúdo semântico sentencial, sobretudo no que se refere a postulação da estruturação em termos de expressões designadoras e predicativas constitui um teste decisivo para uma teoria semântica com pretensões de solucionar a relação entre teoria lógica, ontologia e gramática. Desde a publicação do último livro de Donald Davidson estabeleceu-se um intenso e renovado debate sobre o tema (BURGE, 2007; KING et 
al, 2014; GASKIN, 2008) O primeiro objetivo desse texto é expor as propostas de Davidson (2005) e de Puntel $(2008$; 2001) sobre o problema da predicação. O confronto dessas duas teorizações é pertinente porque elas partem do mesmo marco teórico estabelecido por Frege e Tarski, mas chegam a resultados muito diversos no que se refere às relações entre a descrição do conteúdo semântico sentencial, predicação e postulação de categorias ontológicas. O ponto principal da divergência se dá na concepção do vínculo predicativo e suas consequências ontológicas, mas o cerne da questão está na compreensão do que é mesmo uma unidade semântica básica, se já sempre complexa e predicativa ou se simples e não-estruturada. O segundo objetivo é mostrar que uma reflexão retrospectiva sobre a teoria padrão de Tarski ainda permite uma melhor compreensão do conceito de predicado e da função semântica das expressões predicativas.

\section{Aspectos da teoria da predicação em Tarski}

A proposta semântica de Tarski (1983) gira em torno da possibilidade de se definir conceitos semânticos para uma linguagem, com base no conceito de satisfação de uma sentença aberta ou fechada, em relação a uma sequência de objetos tomada como domínio de referência. Diferentemente de Frege (1962), para quem os conceitos de referência de expressões linguísticas, bem como os conceitos de verdade e de condições verdade para sentenças, eram primitivos, em Tarski é o conceito de condições de satisfação de um predicado que deslancha todo o processo. Mas, na teoria de Tarski um predicado é uma sentença aberta que pode ou não ser satisfeita em relação a domínios de objetos. Desse modo, a função semântica dos predicados não é explicada em termos de referência a conceitos, como em Frege; ao contrário, a conversa sobre conceitos é derivativa em relação à conversa sobre sentenças que podem ser verdadeiras ou falsas em relação aos objetos que pertencem ao domínio de suas variáveis. Nesse ponto, a teoria semântica de Tarski é análoga a de Frege, pois ambos pensam o conceito de conceito como derivado em relação ao conceito de sentença, mais precisamente, ao conceito de função sentencial que, em termos grosseiros, corresponde ao conceito de predicado. Todavia, no modelo teórico tarskiano os predicados, ou funções sentenciais, não têm propriamente referência, pois são ou não satisfatíveis em algum domínio de objetos.

Na proposta de Tarski, os conceitos semânticos são todos eles relacionais e apreendem as relações entre expressões linguísticas de uma linguagem e um domínio de objetos. Uma interpretação referencial da proposta de Tarski não é de todo correta porque o seu conceito básico não é o de referência ou de designação. A relação fundamental da semântica tarskiana é a de satisfatibilida- 
$d e$, que estabelece inclusive o modo como um nome designa um objeto. Porém, a satisfatibilidade é concebida como uma relação entre objetos e certas expressões denominadas funções sentenciais. No que diz respeito à noção de satisfação, poderíamos tentar defini-la dizendo que objetos dados satisfazem uma função dada se esta torna-se uma sentença verdadeira quando, nela, substituímos variáveis livres por nomes desses objetos (TARSKI 1970, §11, p.91). Todavia, nesta formulação, supõe-se a noção de verdade e também a noção de sentença. Por isso, Tarski recorre a uma outra definição:

Indicamos quais objetos satisfazem as funções sentenciais mais simples; e depois estabelecemos as condições sob as quais objetos dados satisfazem uma função composta supondo que sabemos que objetos satisfazem as funções mais simples a partir das quais a função composta foi construída (TARSKI, 1970, \$11, p.91).

No que interessa à teoria semântica, dois momentos estão aí envolvidos. O primeiro, a definição de satisfação de funções simples por objetos e, o segundo, com o uso desta definição, a definição de satisfação de funções compostas. Para a definição de funções simples, o esperado seria a utilização de noções como denotação e referência. E é isso mesmo que Tarski faz em apresentações mais livres:

In fact, semantical concepts express certain relations between objects (and states of affairs) referred to in the language discussed and expressions of the language referring to these objects. Hence the statements which establish the essential properties of semantical concepts must contain both the designation of the objects referred to (thus the expressions of the language itself), and the terms which are used in the structural description of the language (TARSKI, 1983, p.403).

A relação entre as expressões da linguagem objeto e os objetos, bem como entre tais expressões e suas descrições estruturais na metalinguagem, não é senão a relação de designação, que, porém, no esquema tarskiano, ele mesmo é explanado a partir dos conceitos de satisfação e função sentencial (1983, p.1934):

To say that the name $\mathrm{x}$ denotes a given object $a$ is the same as to stipulate that the object $a[\ldots]$ satisfies a sentential function of a particular type. In colloquial language it would be a function which consists of three parts in the following order: a variable, the word "is" and the given name x. (1983, p.194, n1).

\footnotetext{
${ }^{1}$ A noção de satisfatibilidade traz consigo embutida a noção de preenchimento, de Husserl, bem como a noção de saturação de uma expressão insaturada por um argumento, de Frege. A explicitação dessas metáforas fazem parte da teoria semântica desde os seus começos e por meio delas resolve-se 0 problema da relação entre 0 âmbito dos conceitos e o âmbito dos objetos. Mas, o mecanismo pela qual um objeto "satisfaz" uma expressão linguística em geral permanece inexplicado.
} 
Portanto, não é o conceito de designação que explica o de satisfação, mas, sim, o contrário é que é o caso. O problema, então, é a explicitação do que se quer dizer com "estipular que um objeto satisfaz uma função sentencial" sem se recorrer a algum tipo de relação de referência ou designação. Considere-se qual é o papel do sinal " $a$ " na frase "the name $x$ denotes a given object a is the same as to stipulate that the object a... satisfies a sentential function of a particular type". A resposta é tanto simples quanto problemática: $a$ é o próprio objeto, isto é, a primeira letra do alfabeto latino não está ali como signo ou símbolo, mas enquanto sinal ou marca, enfim, como objeto. Por sua vez, a letra "x" está ali sendo usada como signo ou nome do objeto $a$. Disso resulta que uma função sentencial, utilizada para a instituição de um nome para um objeto, seguindo a sugestão de Tarski, é algo do tipo "( ) é x", onde os parêntesis indicam o lugar do objeto (de um domínio qualquer) e a letra "x", por sua vez, é uma variável que se substitui por possíveis nomes de objeto pertencentes à linguagem em questão. Por exemplo, tomando uma inscrição do alfabeto como domínio de referência, podemos construir a seguinte sentença: "a é alfa". Tal sentença estipula que o objeto a, seja a marca de tinta ou o tipo de marca de tinta, denomina-se "alfa", isto é, o objeto a satisfaz a função "( ) é alfa" nessa linguagem. Note-se que alfa, antes dessa sentença, era apenas uma marca ou objeto, tal como a, e torna-se uma expressão pela asserção da verdade da sentença que a estipula como nome de a. Novamente, a analogia com o princípio de contexto fregeano é explícita.

Desse modo, o aparato todo depende da noção de "atribuição de um objeto no dominio a uma variável livre". Uma variável pode ser vinculada ora a um ora a outro objeto do domínio. A variável é um recurso para trazer ao discurso um objeto qualquer do domínio; mas, se ela é utilizada para explicar os nomes, ela mesma não é um nome. Resta uma única alternativa: nas sentenças instituidoras ou estipulatórias, o objeto mesmo faz parte do conteúdo sentencial e a variável apenas marca o lugar para os diferentes objetos para os quais os nomes estão sendo estipulados. Do contrário, o objeto a teria que ser visto como um nome ou expressão, mas desse modo o procedimento inteiro seria circular. A unidade de significação fica reduzida, desse modo, a algo do tipo "() é alfa" e "() é letra". O que é uma evidência de que a base da significatividade é concebida como derivada da noção de instanciação ou aplicabilidade de um predicado, e não da noção de nome e da relação de designação. Os sinais linguísticos são objetos e, se significativos, codificam funções sentenciais que, se calhar, são satisfazíveis por objetos. Para um objeto $\mathbf{x}$ ser o nome de um objeto a, todavia, é necessário que se estipule que o objeto a satisfaz a função sentencial [serdenominado $\mathbf{x}$. Isto é uma decorrência da teoria dos tipos que prevê a distinção apenas entre (0) objetos, (1) funções sentenciais, (2) funções sentenciais de 
segundo nível. As noções semânticas são definidas pela correlação entre esses níveis. Satisfação e designação dizem respeito às relações entre (0) e (1); verdade, equivalência, consequência já seriam conceitos de segundo nível, referentes a correlações entre (1) e (2). A relação de predicação, propriamente dita, embora subsumida no conceito de função sentencial, subjaz implícita na noção primitiva de satisfação, já que, embora o inteiro aparato semântico esteja ancorado num único conceito, uma sentença é um complexo estruturado no qual ao menos duas funções semânticas distintas são articuladas.

Esta leitura, porém, não é capaz de explicar completamente a estratégia tarskiana, pois, seguidamente ali é dito que os predicados nomeiam subconjuntos no domínio. Isto é uma consequência da indistinção das relações de remissão a objetos: todas as expressões significativas "nomeiam" aquilo a que remetem, seja indivíduos, classes, relações, etc. (1983, p.156, n1). As expressões conceituais, ou predicativas, nomeiam no sentido de que o nexo que se estabelece entre elas e os objetos é fruto de uma estipulação de satisfação de uma função sentencial. Não há nada de especial diferenciando, p. ex., as expressões "... é alfa" e "... é uma letra do alfabeto", a não ser o fato de elas, por estipulação, nomearem ou denotarem diferentes conjuntos de objetos. E a diferença delas em relação a “... é Josể não está na sua função semântica, pois, as três estipulam uma condição linguística que determina um conjunto de objetos a depender da sequência de objetos tomada como modelo.

A definição de satisfação estabelece que para uma expressão " $\mathrm{N}$ " ser um nome tem que haver um objeto a que satisfaça a função sentencial " $x$ é $\mathrm{N}$ " de tal modo que se a é nomeado por "José", então a substituição de "N" por "José" produz uma sentença verdadeira; se a é Airton, "N" tem que ser substituído por "Airton" etc. Em outras palavras, a definição de satisfação pressupõe uma estipulação da relação de remissão entre expressões e objetos, remissão essa que a teoria não oferece nenhuma explanação. Pois, embora, na metalinguagem, estejam em jogo apenas os termos de uma linguagem $L$ e os termos usados para descrever estes termos, os termos de $L$ têm de denotar e, para isso, os objetos denotados têm de existir. A relação de denotação entre $L$ e o domínio já tem de estar estabelecida.

Com o conceito de satisfação de uma função sentencial definem-se os conceitos de verdade, de consequência e de equivalência lógicas. As noções de consequência e equivalência caem sob a noção de relação inferencial, pois o que está em questão é já uma relação entre sentenças. O que não é comum, no entanto, é o conceito de verdade também estar entre tais noções, sobretudo tendo-se em vista a proposta de uma definição estritamente semântica e a sugestão de que tal definição recuperaria o cerne das definições clássicas em termos de correspondência e existência. No entanto, Tarski apenas desloca a 
noção de verdade para um nível superior, defendendo simultaneamente a possibilidade de defini-la e a sua vinculação com a relação de remissão entre o linguístico e o extralinguístico. Com efeito, na teoria tarskiana todos estes conceitos são definidos empregando-se uma estratégia semântica, na qual o conceito de satisfação de uma função sentencial por um único objeto ou por uma sequência de objetos é decisivo e primitivo ${ }^{2}$. Portanto, a conclusão de Tarski é que, não obstante o caráter secundário de tais conceitos e relações, todos eles dependem do nexo semântico para a sua definição.

No que diz respeito ao problema clássico da predicação, a conclusão é que nessa teorização a noção de predicado desaparece em favor da noção de sentença satisfativel numa sequência de objetos. Esta seria a relação lógica básica, em vez da relação entre conceito e objeto proposta por Frege. Propriamente falando, as expressões predicativas desaparecem como derivadas de funções sentenciais. Embora nas exposições informais se fale de predicados designando conjuntos de objetos, e até como nomes comuns de propriedades, isso não é propriamente correto, pois o conceito semântico básico é o de satisfação de sentenças abertas ou fechadas em relação a sequências de objetos. Até mesmo, e isso é importante para o que faremos a seguir, os predicados "verdade" e "falsidade" são definidos a partir desse conceito semântico primitivo. Mas não apenas esses: os próprios nomes de objetos e variáveis para objetos são introduzidos via uma sentença aberta do tipo "x é $\mathrm{N}$ ", assim como os nomes comuns e nomes de propriedades.

\section{A verdade como base da predicação}

A tese principal de Davidson pode ser alcançada como uma consequência da proposta de Tarski. Davidson propõe uma teoria da predicação baseada na preeminência do conceito de verdade ${ }^{3}$, como um desdobramento e correção da semântica tarskiana, para se adaptar a uma teoria do significado para linguagens naturais. A proposta é feita também como uma alternativa às teorias proposicionalistas clássicas (fregeanas e russellianas) que explicam as condições de verdade de sentenças com base na suposição de que sentenças expressam proposições, e que concebem os predicados como uma parte da proposição. O ponto de discordância é a suposição de que as partes da senten-

\footnotetext{
2 "[...] it has been found useful, in defining the semantical concepts, to deal first with the concept of satisfaction; both because a definition of this concept presents relatively few difficulties, and because the remaining semantical concepts are easily reducible to it" (1983, p.406-7).

3 "Truth is the prime semantic concept; we could not think or speak in the sense of entertaining or communicating propositional contents without it. The semantic of names, functional expressions, complex singular terms, predicates, quantifiers, variables, and sentential connectives are all subsidiary to the work they do in explaining the truth conditions of sentences" (2005, p.155).
} 
ça são significativas por terem referência, sobretudo as expressões predicativas. Contra isso, Davidson argumenta que

if $[\ldots]$ predicates refer to entities, and this fact exhausts their semantic role, it does not matter how odd or permeable some of the entities are, for we can still raise the question of how these entities are related to those other entities, objects. (2005, p.145).

O ponto principal da crítica de Davidson, pode-se dizer, está em indicar a sobreposição da função semântica e da categorização ontológica, presente na suposição de que alguma entidade faça o papel da predicação:

To say that predicates are functional expressions, and are therefore incomplete or unsaturated, and that what they refer to is similarly full of holes or spaces waiting to be filled in, does not help: entities are entities, whatever we call them.. (2005, p.156).

Davidson rejeita, portanto, tanto a tese de que sentenças designam proposições, quanto a tese de que as partes subsentenciais cumprem sua função semântica por designar um certo tipo de entidade. A solução de Davidson será exacerbar o papel do conceito de verdade, nisso seguindo Frege, e tal como o fizeram Tarski e Quine. Com efeito, a predicação já ali era explanada em termos de verdade. O conceito central é a especificação de condições sob as quais sentenças são verdadeiras de objetos; a partir desse conceito se introduz o conceito de predicação e, por fim, o próprio conceito de conceito ou termo geral.

Todavia, isso é apenas o começo, pois o alvo de Davidson é justamente a concepção, comum aos proposicionalistas, das sentenças como significando proposições e dos predicados como expressões funcionais que, em algum sentido, referem-se a funções supostas como correlatas de entidades abstratas: "[...] sentences do not play the same role in language as singular terms do, and if sentences are not singular terms, then predicates are not functional expressions" (p.145). O ponto de Davidson não é em ontologia, mas em teoria semântica: "The existence of abstract objects is a separate issue. The point of the lesson is that their existence does not belp to explain predication" (p.146). A tese fundante da teoria davidsoniana é que a predicação é uma função semântica, e esta é inteiramente sustentada pela noção primitiva de verdade, não estando portanto baseada e nem exigindo nenhuma distinção ontológica:

[...] if we can show that our account of the role of predicates is part of an explanation of the fact that sentences containing a given predicate are true or false, then we have incorporated our account of predicates into an explanation of the most obvious sense in which sentences are unified, and so we can understand how, by using a sentence, we can make assertions and perform other speech acts. Truth is the prime semantic concept; we could not think or speak in the 
sense of entertaining or communicating propositional contents without it (2005, p.155).

Esta é a lição da teoria semântica de Tarski. A motivação para se retomar essa teoria na discussão sobre a predicação, para Davidson, está em que o lógico polonês "resolveu o problema da predicação que tem intrigado os filósofos por milênios", mesmo sem o saber (p.148). Conforme a exposição de Davidson, Tarski já em 1931, no artigo sobre o conceito de verdade, não exigia entidades como correlatos de sentenças:

[...] Tarski provides no entities at all to which sentences correspond or which sentences name, picture, or otherwise represent. No facts appear in the official apparatus, nor do propositions, either as the meanings of sentences or as halfextensional, half-intensional enitities in the world as in Russell's early theory. (p.155).

[...] any attempt to give a full explication of the semantics of predicates by associating them with single objects of any kind is doomed. It does not matter what the objects are. Platonic ideas or Forms, Aristotelian universals, properties, characteristics, relations [...]. - none of these provides a satisfactory account of the role of predicates.

[...] A theory of truth of the Tarskian sort [...] does not explain the function of predicates by relating them to particular entities which somehow embody generality (2005, p.156).

Davidson nota, entretanto, que as exposições modelo-teoréticas e extensionais obscurecem esse aspecto da semântica tarskiana, ao associarem predicados a conjuntos:

There can be no doubt that Tarski's truth definition, and theories of truth based on them, clearly distinguish between the issue whether properties and other abstract entities exist and the semantic role of predicates. Of course, if some (sencond-level) predicates are true of abstract objects, those objects must exist, but their existence does not explain the role of such predicates. [...] Tarski's method for characterizing truth makes use of set theory, and it is not easy to see how can this be avoided. But this unavoidable assumption of set theory and the existence of sets does not mean that predicates refer to or stand for sets (2005, p.158).

Com efeito, como vimos antes, na teoria de Tarski, o conceito de "ser verdadeiro de" é explanado em termos de satisfatibilidade. Davidson, ao contrário, usa o conceito de verdade para explicar satisfatibilidade e predicação (2005, p.160-61), desse modo retomando algumas intuições semânticas de Frege. Para Davidson, feita essa inversão o problema da predicação é resolvido. Mas, alguém poderia objetar que assim se fornece "an account of how each predicate in a language contributes to the truth conditions of the sentences in which it occurs, but that it gives no general explanation of predication" (Idem, p.161). Então, Davidson conclui: 
It is true that no such general explanation emerges. What does emerge is a meth$o d$ for specifying the role of each and every predicate in a specific language; this role is given by a non-recursive axiom which says under what conditions it is true of any number of entities taken in the order in which its blancks occur. (2005, p.161)

Ao final, o filósofo americano sugere uma teoria do aprendizado de nomes e predicados em termos ostensionais e cooperacionais, a partir do que emergiria a competência linguística. Frases do tipo "This is Peter" e "That is Paul", para nomes, e "This is green" e "That is a book", para predicados. Note-se a similaridade desse mecanismo com a proposta de estipulação na teoria tarskiana. Davidson não explica a diferença dos usos dos termos assim introduzidos. Isso é decepcionante, pois já nas sentenças usadas como exemplos há diferenças. Davidson conclui, porém, e insiste em que o processo se desencadeia pelo fato de que o ouvinte aceita tais frases como tidas por verdadeiras pelo falante e como verdadeiras para si mesmo, e finaliza concluindo que "a contribuição dos predicados para as condições de verdade das sentenças depende e é explanada pela nossa apreensão do conceito de verdade" (Idem, p.163).

Dizer isso ainda não explica o que é um predicado e nem muito menos a função semântica das expressões predicativas. Se passamos para o português, teríamos o seguinte: "Este é Pedro" e "Aquele é Paulo", "Isto é verde" e "Aquilo é um livro". Ora, um fregeano redarguiria prontamente, "é verde" tanto pode ser usado para introduzir um nome individual, como "é Pedro", quanto para introduzir um nome comum, como "é quebrável". Essa duplicidade desaparece no exemplo "Aquilo é um livro", pelo uso da expressão "um". Uma vez aceito que são duas habilidades ou operações distintas, nomear individualmente e nomear coletivamente, nomear e classificar, indicar e diferenciar, etc., pode-se facilmente introduzir a diferença entre nomear e predicar. Essa distinção parece ser básica (BAKER, 2004), além de explicar a diferença inferencial de tomar "Esse é Pedro" e "Esse é azul" como verdadeiras.

De qualquer modo, Davidson não abandona o primado da sentença na explicação das noções semânticas. Pode-se dizer que todas as noções semânticas são derivadas da noção de sentença verdadeira. Nisso ele segue o modelo fregeano, ainda. A distinção entre nomear e predicar é secundária em relação à noção de sentença. As expressões predicativas são distinguíveis na sentença, na medida em que se isole um ou mais termos designadores e se os substitua por variáveis. Com efeito, Davidson mantém a diferença entre a função semântica dos predicados e a dos designadores, pois, por um lado, nomes e predicados são introduzidos pelo mesmo mecanismo; por outro, uma expressão predicativa é caracterizada por "ser verdadeira de entidades que são nomeadas pelas constantes que ocupam seus lugares on são quantificadas pelas variáveis que 
aparecem no mesmo lugar e são ligadas pelos quantificadores" (2005, p.159). Essa caracterização praticamente torna-a indistinguível da noção de sentença. A diferença com relação a Frege é que estas expressões não tem conceitos como referentes.

A vantagem teórica da proposta de Davidson, e de Tarski, está no fato de se eliminar a necessidade de associar as expressões predicativas a algum tipo de entidade especial, diferente dos objetos associados aos designadores. Todavia, a explicação fregeana das expressões predicativas com base nos conceitos de sentido (Sinn) e de conceito (Begriff), ambos como ingredientes não destacáveis do conteúdo sentencial, em Tarski e Davidson está preservada e condensada no conceito de verdade sentencial e de uma expressão ser verdadeira de objetos de um domínio de referência, pois esses conceitos agora são a base de explanação das propriedades inferenciais associadas à ocorrência de uma expressão predicativa e não outra numa sequência de sentenças. De qualquer modo, a proposta de Davidson ainda permite que se fale em predicados e que se diferencie a função semântica da predicação no plano da descrição semântica sentencial, embora essa função não esteja comprometida com a postulação de uma entidade especial correlata.

\section{A primariedade dos termos proposicionais}

No artigo de 2001 e no livro de 2008, Puntel aceita em grande medida a linha de argumentação de Davidson, mas chega a uma proposta muito diferente sobre o nexo predicativo, a qual consiste em eliminar a primariedade tanto dos nomes quanto dos predicados em teoria semântica, a partir de uma interpretação forte do princípio do contexto fregeano, pela qual o conteúdo das partes subsentenciais é ele mesmo sentencial. A unidade semântica básica não é concebida a partir de funções subsentenciais, mas é ela mesma já sentencial, embora não estruturada. Note-se que essa solução está embutida na solução de Tarski e Davidson, pois ali o conceito de nome é subsumido ao de predicado, e por sua vez, o conceito de predicado é subsumido ao de verdade sentencial. Puntel simplesmente dá o passo seguinte e diz que o conteúdo dos predicados, e também dos nomes, é já proposicional, retomando a perspectiva aberta por Frege, mas implicando uma consequência inaceitável para o pensador de Jena.

O problema de Puntel é a conexão entre semântica e ontologia (OLIVEIRA, 2014). O seu diagnóstico é que a estrutura sujeito-predicado tem confundido os filósofos e que ela precisa ser abandonada; os argumentos são que mesmo se, além da categoria de substância, outras categorias ontológicas forem introduzidas e aceitas (p. ex. evento, processo, e outras), uma estrutura semântico-ontológica mais fundamental é ainda pressuposta por todas essas 
teorias: a estrutura "diádica" indivíduo-universal ou sujeito-atributos (atributos: propriedades e/ou relações). Essa estrutura categorial constitui o nível fundamental em relação a todas as outras, sendo, portanto, pressuposta por essas outras categorias. Essa afirmação baseia-se no fato inegável de que as outras categorias ontológicas (como eventos, processos, etc.) são compreendidas como entidades que tem propriedades e estão em relação com outras entidades. Isso torna-se manifesto pelo fato de serem essas categorias articuladas na estrutura sintático-semântica da linguagem de predicados de primeira ordem. Em sua interpretação padrão essa linguagem possui exatamente a estrutura semântica que corresponde à estrutura diádica indivíduos-universais cifrada na distinção entre termos singulares e termos gerais, cuja proveniência é a tradicional estrutura predicativa.

A segunda objeção de Puntel é que a semântica da linguagem de predicados de primeira ordem baseia-se completa e fundamentalmente no princípio de composicionalidade, que, aplicado às sentenças, diz que o significado (ou valor semântico) de uma sentença é uma função dos significados (ou valores semânticos) de seus componentes subsentenciais. De acordo com esse princípio, admite-se uma independência, pelo menos relativa, dos valores semânticos dos componentes subsentenciais. Assim, o termo singular tem como seu referente próprio o denotado; o predicado — pelo menos em uma semântica realista - o seu próprio designado, o atributo. O referente de um termo singular (e/ou nome próprio) é chamado de modo geral e não específico de "objeto" na filosofia analítica (PUNTEL, 2001, p.7-8). Isso é claro nos modelos de Frege, Tarski, Quine e Davidson, os quais mantém um lugar inquestionado para a noção de objeto, enquanto algo individual e particular, e para a noção de um predicado ser verdadeiro de um objeto. Desse modo, nesse modelo uma sentença é uma articulação de funções semânticas distintas cuja unificação tem sido um problema sem solução (REICHARD, 2014).

Como alternativa, Puntel propõe uma teoria na qual esse privilégio da relação de predicação é abandonado, juntamente com o princípio da composicionalidade. A proposta baseia-se nos seguintes passos. Primeiro, para evitar a estrutura sujeito-predicado das sentenças (atômicas), elabora-se uma linguagem que seja isenta de termos singulares (nomes próprios) e de predicados (termos gerais), os quais seriam responsáveis pela ontologia substancialista das linguagens naturais indo-europeias (2001, p.9), por meio da adoção de uma versão forte do princípio do contexto, formulado nos termos de Frege. Na formulação de Puntel, esse princípio é denominado de "Princípio de Contextualidade Sentencial (PCTS)", e é uma reelaboração do princípio formulado por Frege em 1884: "Somente no contexto de uma sentença as palavras tem um significado" (FREGE 1987, p.62; PUNTEL, 2001, p.8). Na teoria proposta, termos singulares e 
predicados são radicalmente eliminados das sentenças básicas da nova linguagem, no tocante ao seu estatuto semântico, em favor de expressões primárias que são já sentenciais:

As sentenças que resultam dessa eliminação serão chamadas sentenças primárias. São sentenças da forma "verdeja", "chove", "leiteia", "mamãe" (tomada como abreviação de uma sentença), e semelhantes. No português filosófico poder-seia dizer adequadamente: "está F-zando", "F-zar" ou algo semelhante. (Mas "ser F" não o fará, uma vez que essa expressão designa uma propriedade (de acordo com uma visão realista das propriedades), uma entidade que requer uma outra entidade - um sujeito/substrato - da qual ela seja predicada) (PUNTEL 2001, p.9).

Estas expressões primárias são dotadas de conteúdo semânticoinformacional não estruturado:

Sentença primária, tem (ou expressa) um conteúdo informacional que pode ser designado de estado de coisas primário, ou, mais curto, primestado. Em um aspecto importante, essa entidade é o que, em uma lógica de predicados de primeira ordem, é, em geral, tomado como o designatum de um predicado (PUNTEL 2001, p.13).

Desse modo, os "antigos" predicados não estão contidos na linguagem reinterpretada como predicados, uma vez que predicados como tais foram eliminados. Mas a "função expressiva" exercida por essas expressões, que na linguagem da lógica de predicados de primeira ordem são consideradas "predicados", reaparece ou é mantida na nova linguagem teórica na forma de uma sentença primária cuja forma geral é "está F-zando", a qual tem como conteúdo um estado primitivo, tal como "Chove" e "Neva", que não é um atributo de uma substância ou indivíduo.

Esse estado de coisas primário é o conteúdo informacional compreendido no uso da expressão "F" em sentenças primárias da forma "está Fzando" (PUNTEL 2001, p.14). Retomando a tese fregeana, os termos singulares e gerais, objetos e conceitos, são introduzidos na descrição semântica dessas sentenças primárias como derivados da análise. Essa proposta diz respeito diretamente ao conceito mesmo de sentença mínima (oração, frase) significativa e de conteúdo sentencial (proposição, fato, estado de coisas). Desde Platão e Aristóteles, o modelo padrão é de algo já articulado nos termos do famoso mote "dizer algo de algo". Na proposta revolucionária de Frege, em 1879 (2007), esse modelo sofreu uma modificação essencial, pois ali, embora fosse mantida a estruturalidade no plano sentencial, o conteúdo sentencial foi concebido como não estruturado (FREGE 1990, p.173; 2007, \3, p.61), de tal modo que, como afirmou explicitamente Frege, poder-se-ia operar com um único predicado para todas as sentenças. Puntel explora justamente esta tese.

Como exemplo de análise, Puntel sugere que a sentença "Sócrates é um filósofo", cuja forma sintática é do tipo sujeito-predicado, seja analisada, de 
acordo com a semântica e ontologia aqui esboçada, do seguinte modo: Existe um x tal que x é ("é" no sentido de "deve ser interpretado semântica e ontologicamente como") a configuração $S$ dos estados primários $P 1, P 2, \ldots, P n$, e existe um estado primário $P i$ tal que $P i$ é o estado primário expresso pela sentença primária 'filosofa' e $P i$ é um componente constituinte de $S$ (PUNTEL 2001, p.15). Desse modo, essa sentença expressaria um fato complexo, constituído por fatos primários, os quais são eles mesmos conteúdos informacionais de sentenças básicas. A análise final dissolve os termos "Sócrates" e "é um filósofo" em configurações de fatos primários, no estilo da técnica sugerida por Quine para dissolver os termos singulares. A diferença é que Puntel entende que também os termos gerais são assim dissolvidos, restando no final apenas sentenças primais que são ou não verdadeiras, isto é, que expressam fatos simples, tendo como gancho a afirmação de Frege de que a questão "O que é um fato?" deveria ter como resposta "um fato é um pensamento que é verdadeiro”. A identidade entre um estado de coisas (primário) e uma proposição verdadeira pode ser vista como um caso limite da relação de correspondência (PUNTEL 2001, p.16).

Essa tese é explorada por Puntel na forma de um princípio semântico generalizado, que submete a função e o valor semântico de toda e qualquer expressão à função semântica sentencial. O ponto principal consiste na adoção do princípio do contexto, do qual são retiradas consequências tanto ontológicas como lógico-semânticas ${ }^{4}$. Puntel, entretanto, adota uma versão na qual pretende superar uma certa ambiguidade das formulações de Frege, substituindo o termo "Bedeutung" pela expressão "semantischen Wert". Desse modo o princípio fica assim formulado: "(KTP) Apenas no contexto de uma sentença as expressões linguísticas têm um valor semântico” (PUNTEL 1990, p.142).

A importância da adoção deste princípio emerge quando se considera um outro princípio que também devemos a Frege, a saber, o princípio de que o sentido/referência de uma sentença é uma função do sentido/referência de suas partes componentes. Neste princípio é que se funda o principal critério lógico para termos e definições, a saber, o critério de substitutividade salva veritate. Equalizando a terminologia, Puntel o formula assim:

\footnotetext{
${ }^{4}$ A formulação deste princípio remonta a Frege. Em seu livro Die Grundlagen der Arithmetik (1987), ele utiliza como princípio as seguintes teses: "Man muss aber immer einen vollständiger Satz ins Auge fassen. Nur in inm haben Wörter eigentlich eine Bedeutung. [...] Es genügt, wenn der Satz als Ganzes einen Sinn hat; dadurch erhalten auch seine Theile ihren Inhalt" [§ 62]. Mais precisamente: "Wir stellten... den Grundsatz auf, dass die Bedeutung eines Wortes nicht vereinzelt, sondern im Zusammenhange eines Satzes zu erklären sei..." [§ 106].
} 
(KPP) O valor semântico de uma expressão complexa é funcionalmente dependente apenas dos valores semânticos de suas partes componentes logicamente relevantes. (PUNTEL 1990, p. 143)

(KTP) e (KPP) podem ser interpretados como compatíveis ou não, ou ainda como estando em uma relação de complementaridade, tendo um ou outro como primário. Puntel, todavia, opta pela incompatibilidade e pretende fundamentar o princípio do contexto como básico para uma teoria semântica.

A justificação da incompatibilidade se dá a partir de uma leitura dos dois princípios em que ambos são tomados no seu sentido mais forte. A questão refere-se ao modo como se explicita a estrutura semântica das expressões complexas, sobretudo das sentenças. Puntel toma o princípio da composicionalidade como implicando que o valor semântico de uma expressão estruturada pressupõe como já determinados os valores semânticos das suas partes componentes. Ou seja, o valor semântico de uma parte de uma sentença seria determinado prévia e independentemente de sua ocorrência em uma dada sentença. Ora, o princípio do contexto diz que justamente isto não se dá, pois apenas no contexto de uma sentença uma expressão linguística tem valor semântico (1990, p.146). Dada esta incompatibilidade, Puntel propõe uma teoria semântica na qual "o valor semântico das expressões subsentenciais é determinado a partir da perspectiva das condições de verdade das sentenças" (1990, p.147). Assim, uma expressão tem valor semântico na medida em que ela contribui para as condições de verdade das sentenças em que ela ocorre.

Entretanto, a concepção tradicional de sentença, como analisável em termo-sujeito e termo-predicado, parece ir contra este direcionamento, quando associada a uma teoria dos termos singulares que postula uma referência direta a objetos ou indivíduos. Contra esta concepção, Puntel desenvolve uma versão radical do princípio do contexto, na qual desaparece também esta possibilidade:

Versão holista do princípio do contexto: Nesta formulação a expressão "sentença" designa uma sentença complexa, no caso extremo a linguagem completa, e a expressão "expressão linguística" bem como os componentes subsentenciais designam também sentenças abaixo do nível da sentença complexa (visada) ou, respectivamente no caso extremo, sob o nível da linguagem completa (1990, p. 156).

Esta versão exige que os elementos subsentenciais (termos singulares e gerais, termos lógicos) sejam esclarecidos também em termos sentenciais. Principalmente, a noção de termo singular não mais será vista atomisticamente; ao contrário, é concebida como uma sentença abreviada ou elíptica. Disso se segue que a significação dos termos singulares tem de ser concebida como uma configuração de proposições primárias ou simples. Além disso, analisando a lin- 
guagem dos atos de fala, Puntel procura mostrar que os atos de referir e caracterizar são momentos dependentes e derivados do ato primário e global de asserir (1990, p.161). Este ponto é tomado como o fundamento geral do princípio do contexto, no sentido de que os valores semânticos dos termos singulares e dos predicados se constituem como momentos ou partes do inteiro valor semântico de uma asserção, de um ato de fala, cuja expressão Puntel entende ser já uma sentença, isto é, que o valor semântico das partes é logicamente dependente do valor semântico do todo, determinando-se a partir do todo sentencial (holismo). Em termos semânticos e ontológicos isto tem como consequência imediata o abandono da tese de que o mundo seja composto de "objetos, propriedades ou relações". Com efeito, Puntel mantém que:

Uma ontologia desse tipo é excluída pela versão forte do princípio do contexto. [...] Da versão forte decorre antes que "Mundo" deve ser concebido como a totalidade das Proposições/Verhalten "existentes". Os assim denominados Objetos/indivíduos respectivamente são concebidos como configurações de Proposições/Verhalten primários. (1993, p.285)

A partir destas indicações Puntel propõe, então, uma reformulação de três conceitos básicos, a saber, os de sentença, proposição e mundo, os quais serão a base para a sua redefinição da noção de verdade. Ele sugere que as sentenças, enquanto formações simbólicas têm um valor semântico-informacional, a saber, a proposição por ela expressa(1990, p.162), concebido como possuindo três níveis de estruturação: sintático, semântico e pragmático. A novidade está em que nenhum deles pode ser definido isoladamente. No que se refere ao valor semântico de uma sentença Puntel faz as seguintes distinções:

(1) O valor semântico-informacional (vs-i), ou direto, da sentença é a Proposição.

(2) Em relação ao vs-i:

(2.1) O valor semântico-lingüístico da sentença é uma função do contexto de enunciação da sentença no vs-i, isto é, na Proposição.

(2.2) O valor semântico-sistemático da sentença é a intensão do valor direto ou vs-i, e (indireto ou mediado) da sentença mesma; a intensão é uma função que relaciona em cada mundo possível a extensão do valor direto ou vs-i.

(3) O valor semântico-dimensional da sentença é a extensão do vs-i. A extensão é o conjunto de mundos (possíveis), aos quais o vs-i, i.é., a proposição pertence, como parte, ou nos quais a proposição "é o caso", portanto, nos quais a sentença é "verdadeira"(1990, p.176-7).

Desse modo, a sentença, conforme a versão forte do princípio do contexto, é a forma linguística primária e central, e o atributo é a entidade inteligível fundamental, sendo o ' $\mathrm{x}$ ', em 'P(x)', como variável individual, posto como dependente da sentença. $\mathrm{O}$ que significa dizer que o objeto ou indivíduo, enquanto tomado como o valor de ' $x$ ', não pode ser pressuposto como independente do atributo que é indicado através de ' $\mathrm{P}(\mathrm{)})$ '. ' $\mathrm{P}(\mathrm{x})$ ' tem assim um caráter secundário, derivado (1990, p.188). Nesta concepção a noção principal é a 
ideia de determinação como fundamental para a noção de entidade. E as únicas entidades determinadas em si mesmas são os atributos, pois os objetos/indivíduos determinam-se a partir dos atributos. Um indivíduo consiste em uma configuração de atributos (1990, p.189-90). Ou seja, proposição não é senão um "atributo realizado" (PUNTEL 1993, p.285). E, "um atributo é determinado ou realizado apenas quando ele pertence a um Mundo" (PUNTEL 1990, p.190).

As sentenças primárias expressam proposições primárias, as quais são compreendidas como "atributos realizados ou determinados", as quais não pressupõem nenhum objeto previamente constituído como componente, mas também não o de predicado ou de universal. Os objetos são configurações, formações (Gebilde) de proposições primárias. Todavia, um fato primário (Verbalt) não pode ser entendido como "propriedade" ou "qualidade", pois obviamente estas noções pressupõem objetos/indivíduos, ou um substratum como suporte. Os indivíduos/objetos são concebidos como também sendo "Verbalts", isto é, um Verbalt [secundário] de Verbalts primários (1990, p.225, 229). Por sua vez, o Mundo é a totalidade das Verhalts (existentes). Uma outra consequência é que um indivíduo não pode ser determinado isoladamente, mas apenas em um mundo (1990, p.233, 237). Exemplos de possíveis sentenças primárias são aquelas formadas pela expressão "Es verbält sich (so und so)", ("Acontece assim e assim", "Está assim e assim"), as quais não pressuporiam um sujeito/objeto. Exemplos em português: "Chove", "Neva", "Faz sol" (1990, p.193). A apresentação formal dessa entidade seria feita através de um par ordenado representando o atributo e a sua realização, seguindo o modelo de Nusenoff (1979) (PUNTEL, 1990, p.202-4). Este tipo de representação deixa claro que as proposições primárias não contêm nenhuma variável individual, na medida em que recorrem ao predicado "conjunto vazio" para falar de um predicado não realizado.

A posição de Puntel pretende ser um desdobramento da proposta de Quine de eliminação dos termos singulares em favor de termos gerais. A proposta de Quine restava dependente da noção de termo geral e de expressão predicativa. No entanto, uma vez que esses conceitos eram explicados em termos de função e verdade sentencial, Puntel sugere que o conceito primitivo seja justamente o de sentença não estruturada verdadeira, não em relação a um objeto já destacado, mas em relação ao mundo. A resultante da teoria de Puntel é que as expressões predicativas são eliminadas da teoria da descrição semântica, do mesmo modo que as expressões designadoras, enquanto derivadas de uma função semântica mais primitiva. $\mathrm{O}$ uso, e a função semântica, de nomes próprios, nomes comuns, predicados, seria dependente da significativi- 
dade do uso de expressões linguísticas básicas usadas para expressar a ocorrência de estados primários.

Nesse sentido a proposta de Puntel é uma reafirmação das intuições iniciais de Frege, a saber, de que a estrutura sujeito-predicado era inadequada para a análise lógica e de que o conteúdo semântico sentencial era nãoestruturado, embora as sentenças o fossem. Por outro lado, a proposta de Puntel significa uma radical ruptura com a teoria clássica da predicação, pois sugere que na base da significatividade está numa relação de identidade entre fatos primários e sentenças primárias, os quais ambos são não estruturados.

\section{A função semântica das expressões predicativas}

Na teoria proveniente de Frege e Tarski, o real, seja lá o que isso for, não faz parte do conteúdo semântico expresso por uma sentença, não sendo assim possível identificar proposição (Gedanke, semantic content) e fatos (Tatsache, conteúdo semântico). A tese de que fato é a proposição verdadeira de modo algum implica tomar um pelo outro, pois isso significaria eliminar justamente o conceito primitivo "verdadeira". Esse conceito indica uma relação que não pode ser a de identidade, pois os relatas aí não tem as mesmas propriedades. Além disso, na teoria de Puntel, assim como em Quine (1960) e Wittgenstein (1993) antes dele, ao se reduzir a estrutura do conteúdo semântico sentencial a um único tipo semântico para evitar o problema da unidade da estrutura proposicional acaba-se por torná-lo mais evidente, pois, como então explicar a composição dessas novas unidades?

O que permanece é a solução fregeana de distinguir o elemento semântico do valor referencial, e, mais ainda, a solução tarskiana de subsumir o conceito de predicado ao conceito de sentença aberta no que, outra vez, está preservada a solução fregeana de identificar os conceitos com a função predicativa, ao menos no sentido de não se introduzir conceitos separadamente de expressões predicativas que, em última análise, são tão somente sentenças incompletas.

Ao final, esta solução fornece um modelo mais adequado tanto para a natureza do conceitual quanto da estrutura predicativa sem precisar introduzir uma tese ontológica mais forte, seja a de Puntel seja a de Quine, além de explicar a unidade da proposição por meio seja do enlace entre função e argumento seja do encaixe entre parte destacável e parte indestacável de uma sentença.

A proposta de Puntel não é compatível com as melhores teorias disponíveis, linguísticas e formais. Com efeito, as quatro matrizes de teorias formais de fundo, Teoria de Conjuntos, Mereologia, Lógica de predicados e Teoria de Categorias, enquanto linguagens básicas de análise, tem sua base justamente na articulação de dois papéis semânticos dos quais um equivale ao con- 
ceito de predicação (DÜMONT, 1999). Em Linguística a teoria da predicação e a consequente suposição da estruturalidade da sentença é a pressuposição básica inquestionada pelas diferentes teorias em uso, ao ponto de a estrutura predicativa ser posta como um universal linguístico (BAKER, 2004; BOGDAN, 2009). Todavia, a questão diz respeito tanto à necessidade quanto à exequibilidade dessa tese em termos semânticos e também ontológicos. Já Frege, e também a escola polonesa posterior, recusou a necessidade de introdução de objetos gerais para dar conta dos nomes comuns. Por isso, não faz sentido criticar a lógica formal, em nenhuma de suas variações, como comprometida com a suposição ontológica das metafísicas da substância. Claramente, as teorias de Davidson e Puntel emergem de um movimento que começa com (1) o pleno reconhecimento da distinção entre predicados e nomes (FREGE, 1990; TARSKI, 1983); (2) passa pela proposta de operar apenas com nomes (WITTGENSTEIN, 1993); depois (3) pela dissolução e a relativização da oposição entre termos singulares e termos gerais em Ramsey (1990); (4) a proposta de operar apenas com predicados (QUINE, 1960); (5) a proposta de Tarski-Davidson, retomando parte da proposta fregeana de subsumir os predicados na função de asserção (DAVIDSON, 2005); por fim, (6) a proposta de abandonar a própria distinção (PUNTEL, 1990) em favor de uma preeminência da função semântica das sentenças. Contudo, esses passos chocam-se com as teorias linguísticas contemporâneas que reconhecem a distinção e a explicitam recorrendo à estrutura argumento-função, muitas vezes fazendo referência explícita a Frege (BAKER, 2004; BRAIDA, 2014), e também com as melhores teorias formais de fundo que introduzem estruturação para além daquela reconhecida pelo cálculo de proposições.

A avaliação é que estas duas teorias são o resultado da conflação entre a função semântica dos predicados com a função semântica sentencial, como desdobramento de uma interpretação coerencial-holista do princípio do contexto fregeano (BRAIDA, 2013) e da tese da primariedade do conceito de verdade usado por Tarski e Quine como aplicável diretamente às expressões predicativas na forma primária " $F$ ser verdade de $x$ ". Todavia, enquanto Davidson sugere que se aprofunde a análise na direção da sentença para o predicado, Puntel sugere a direção inversa. Seja como for, ambos tomam a sentença (ou a asserção sentencial) como função semântica básica. Essa conflação termina por indistinguir nomear e predicar e, assim, por não explicar a função semântica dos predicados ao eliminar a própria estrutura predicativa como um efeito superficial da linguagem. Ao remeter todos os conceitos semânticos ao conceito primitivo de sentença verdadeira, a solução de Davidson não é diferente da solução de Puntel, pois a própria ideia de predicação torna-se dispensável, substituída pelo conceito de "ser verdadeiro de", o qual permanece inex- 
plicado porque primitivo, o que é análogo ao caráter primitivo da relação de identidade entre fato primário e sentença primária verdadeira em Puntel.

A consequência de ambas as teorias é a eliminação do conceito de predicado e também a dispensa da tese da estruturalidade do conteúdo semântico. A minha sugestão é que essas consequências, primeiro, são incompatíveis com as teses linguísticas contemporâneas e, segundo, implicam a inconveniente dissolução da distinção entre nomear, predicar e asserir. Seja do ponto de vista das teorias linguísticas seja o das teorias formais, o holismo subjacente à tese de Puntel implica a confusão entre a função gramatical e o conceito expresso por uma expressão, sob o mal-entendido mais básico da suposição da identidade entre a estruturação gramatical e a estruturação ontológica embutida na tese da identidade entre sentenças primas e fatos primos. O cerne do problema está na eliminação da predicação, aquele núcleo que Platão, Aristóteles, Frege e Tarski perceberam como o cerne do linguístico e do lógico. Ao eliminar a predicação, Puntel elide a distinção entre linguagem e mundo, entre palavra e entidade. A raiz do problema parece ser a adoção do conceito de "ser verdadeiro de", enquanto aplicável diretamente a qualquer expressão linguística, ou então enquanto fonte de todo conteúdo codificável por uma expressão linguística, o qual sugere que a relação entre linguagem e mundo seja da ordem cognitiva e já conceitual (BRAIDA, 2014), no sentido de que a significatividade seria uma consequência de uma operação de aplicação de uma cláusula a um objeto: para falar em termos fregeanos, em Davidson e Puntel o sentido (Sinn) de um signo (Zeichen) é pensado já como conceitual, portanto, como sendo uma condição de verdade, isto é, uma cláusula sob a qual os objetos caem ou não. Todavia, se esses são os termos fregeanos, esse conceito de sentido não é fregeano, pois Frege distinguiu claramente entre sentido e conceito. O ponto crítico é a consequente eliminação da teoria lógica ou gramatical da diferença entre indicar um objeto sem determiná-lo e indicar um objeto por meio de uma determinação ou classificação, diferença essa refletida na distinção entre termo singular e termo geral na semântica tarskiana, os quais ambos são necessários para compor um termo sentencial que pode ser verdadeiro ou falso.

\section{Referências}

BAKER, M. C. Lexical Categories: Verbs, Nouns, and Adjectives. Cambridge UP, 2004.

BOGDAN, R. J. Predicative minds: the social ontogeny of propositional thinking. Cambridge: MIT Press, 2009.

BRAIDA, C. R. "Sobre a versão coerencial da noção de verdade”. In: Peri, v.1, n.1, p.83-103, 2009. 
. Ensaios Semânticos. Florianópolis: Rocca Brayde, 2013.

. "Estrutura predicativa e significatividade". In: Aurora, v.26, n.39, p.533-561, Jul/Dez 2014.

BURGE, T. "Truth and predication by Donald Davidson". In: The Journal of Philosophy, v.104, n.11, p.580-608, Nov 2007.

DAVIDSON, D. Truth and Predication. Cambridge: Belnap Press, 2005.

DÜMONT, J. Formal-ontologische Kategorien in der Mathematik: Eine systematische Untersuchung zur ontologisch-kategorialen Problematik mathematischer Entitäten. München: Herbert Utz, 2000.

FREGE, G. Grundgesetze der Arithmetik. 2. Aufl. Hildesheim: G. Olms, 1962 [1893].

. Die Grundlagen der Arithmetik. Stuttgart: Raclam, 1987 [1884].

Olms, 2007.

. Begriffsschrift und andere Aufsätz̨e. Hrsg. I. Angelelli, Hildesheim: G. . Kleine Schriften. 2. ed. Hildesheim: G. Olms, 1990.

GASKIN, R. The unity of the proposition. Oxford: Oxford UP, 2008.

KING, J. C. et al. (ed) New thinking about propositions. Oxford: Oxford UP, 2014.

NUSENOFF, R. E. “On representing propositions”. In: Journal of Philosophical Logic 8, p.505-508, 1978.

OLIVEIRA, M. A. A ontologia em debate no pensamento contemporâneo. São Paulo: Paulus, 2014.

PUNTEL, L. B. "O conceito de categoria ontológica: um novo enfoque”. In: Kriterion, n.104, p.7-32, 2001.

- Estrutura e ser: um quadro referencial teórico para uma filosofia sistemática. São Leopoldo: Ed. Unisinos, 2008.

-Wabrheitstheorien in der neueren Philosophie. Darmstadt: Wissenschaftliche Buchgesellchaft, 1993.

. Grundlagen einer Theorie der Wabrheit. Berlin: de Gruyter, 1990.

QUINE, W. Word and Object. Cambridge, Mass.: M.I.T. Press, 1960.

RAMSEY, F. P. Philosophical Papers; ed. D. H. Mellor. Cambridge: Cambridge UP, 1990. 
REICHARD, U. R. “Objects, Concepts, Unity”. In: STALMASZCZYK, P. (ed.), Philosophy of Language and Linguistics: The Legacy of Frege, Russell, and Wittgenstein. Berlin: De Gruyter, 2014, p.213-224.

TARSKI, A. Logic, Semantics, Metamathematics. Ed. by J. Corcoran, and transl. by J. H. Woodger. 2.ed. Indianapolis: Hackett, 1983.

. "The semantic conception of truth and the foundations of semantics". In: LINSKY, L. (ed.) Semantics and the philosophy of language. Urbana: Univ. of Illinois Pr., 1970.

WITTGENSTEIN, L. Tractaus Logico-Philosophicus. Trad. L. H. Lopes dos Santos. São Paulo: Edusp, 1993.

E-mail: celso.braida@ufsc.br

Recebido: $02 / 12 / 2016$

Aprovado: 11/04/2017 